\title{
Tapentadol in the management of cancer pain: current evidence and future perspectives
}

This article was published in the following Dove Medical Press journal: Journal of Pain Research

\author{
Hans G Kress' \\ Flaminia Coluzzi ${ }^{2}$ \\ 'Department of Special Anesthesia \\ and Pain Medicine, Medical University, \\ Vienna General Hospital, Vienna, \\ Austria; ${ }^{2}$ Department of Medical and \\ Surgical Sciences and Biotechnologies, \\ Unit of Anesthesia, Intensive Care and \\ Pain Medicine, Sapienza University of \\ Rome, Polo Pontino, Latina, Italy
}

Correspondence: Hans G Kress Department of Special Anesthesia and Pain Medicine, Medical University, Vienna General Hospital, Waehringer Guertel 18-20, A-1090 Vienna, Austria Email hans-georg.kress@meduniwien. ac.at

\begin{abstract}
Thanks to the progress in early diagnosis and treatment of cancer, the life expectancy of cancer patients has now increased. Patients are, therefore, more likely to experience their individual cancer pain as a chronic pain. As a consequence, long-term treatment of cancer-related pain and oncological therapy-related pain are a major need for all patients and a challenge to all healthcare professionals. Tapentadol is a centrally acting analgesic drug characterized by two synergistic mechanisms of action, since it acts at the $\mu$-opioid receptor (MOR) and inhibits noradrenalin re-uptake (NRI). Therefore, tapentadol has been considered the first of a new class of drugs, MOR-NRI. Tapentadol has been tested in different populations of cancer patients (opioid-naive and -pretreated), such as those with pain of mixed etiology, patients with pain from hematological malignancies and patients experiencing pain conditions due to anticancer treatment. According to available evidence, tapentadol prolonged release was well tolerated and effective in cancer pain patients. In randomized, double-blind and active-controlled trials it proved non-inferior to standard opioids like morphine or oxycodone in the management of moderateto-severe cancer pain, both in opioid-naive and in opioid-pretreated patients. The good analgesic efficacy may be partly due to the action of tapentadol on neuropathic pain components. Together with the low rate of gastrointestinal adverse effects and the overall favorable safety profile, tapentadol can be considered a good option in cancer pain patients, who can suffer frequently from nausea, vomiting, constipation or other events that further reduce their quality of life.
\end{abstract}

Keywords: cancer pain, tapentadol, neuropathic pain

\section{Introduction}

Pain is highly prevalent in patients with cancer. Up to two-thirds of patients report pain when the disease is at an advanced stage; $\sim 60 \%$ of patients on anticancer treatment are affected with pain, and $33 \%$ of those on curative therapy complain of this condition as well. ${ }^{1,2}$ In approximately two-thirds of patients, cancer pain results from the tumor burden, including metastasis of bones or soft tissues, while in $25 \%$ the pain can be attributed to cancer treatment by surgery, radiation or chemotherapy. ${ }^{1,2}$ In cancer patients, pain is rated as moderate or severe in $\sim 40 \%$ of cases. ${ }^{2}$ Pain is associated with interference with daily activities, sleep, mood and social interactions. ${ }^{1,3}$ Thanks to the progress in early diagnosis and treatment of cancer, life expectancy of cancer patients has now increased; therefore, patients are more likely to experience their cancer pain as chronic pain. As a consequence, long-term treatment of cancer-related pain is a major need for all patients and a challenge to all healthcare professionals involved in the care of these patients. However, despite existing recommendations to assess and manage pain, ${ }^{4-8}$ the 
management of cancer-related pain is often suboptimal and patients are regularly undertreated. ${ }^{1,8-12}$ In a recent European survey, $50 \%$ of cancer patients believed that their quality of life was not a priority for the healthcare professionals. ${ }^{9}$ Cancer patients are often elderly and present a number of comorbidities, making treatment even more challenging. ${ }^{13}$

Cancer pain shares the principal mechanisms of other types of pain. In $60 \%$ of cancer patients, the predominant cause of pain was nociceptive, in $20 \%$ the dominant component was neuropathic, and the remaining $20 \%$ showed a combination of neuropathic and nociceptive pain (so-called mixed pain). ${ }^{14}$ Thus, some $40 \%$ of cancer patients may suffer from a neuropathic component of their pain. Indeed, bone pain resulting from the metastatic involvement of the skeletal structures can be considered a typical mixed pain. ${ }^{15,16}$ Moreover, cancer pain can also result from anticancer therapies. ${ }^{14,15,17}$ Finally, cancer patients may have pain independently from their oncological disease, due to other comorbidities.

Tapentadol is an analgesic drug that combines synergistically $\mu$-opioid receptor (MOR) agonism and noradrenalin re-uptake inhibition (NRI) in one molecule. It appears to be unique to date, and therefore it has been classified as the only molecule belonging to a new class of centrally acting analgesics, designated MOR-NRI. ${ }^{18}$ Tapentadol appears to be different to classical opioids and may thus be a suitable choice for the treatment of chronic, neuropathic and mixed pain. ${ }^{19}$ This relatively new concept has been strengthened and expanded to other drugs (tramadol, buprenorphine, loperamide, cebranopadol) by Raffa and Pergolizzi, who stated that the categorization of all analgesics that have any component of opioid mechanism of action into the same class is anachronistic and misleading. ${ }^{20,21}$

Tapentadol has been tested in different populations of cancer patients, such as those with pain of mixed etiology (opioid-pretreated or -naive patients), with pain from hematological malignancies, and patients experiencing pain due to anticancer treatment.

Based on the authors' experience and the analysis of the available literature, this narrative review presents and discusses the current evidence on the use of tapentadol in the management of cancer pain. The lack of a systematic search for evidence should be taken into account.

\section{Clinical evidence for tapentadol in the treatment of mixed pain in cancer patients}

Randomized, placebo-controlled clinical trials in cancer pain patients are a true challenge. Recruitment is hampered by the requirement of a study population of cancer patients that have no other major confounding factors on pain outcome - ie, to find cancer patients with a severe pain, but without relevant comorbidities and interacting drug treatments, which are major recruitment issues. Most suitable patients will likely undergo studies for cancer treatment instead of going into a cancer pain study.

On the other hand, many studies on cancer pain lack an active comparator, and therefore, efficacy and tolerability outcomes are always influenced by comedication and rescue medication. This is a major difference of studies on cancer pain to those on noncancer pain.

With these limitations in mind, the available relevant studies on the use of tapentadol in cancer pain treatment will be discussed.

\section{Randomized, double-blind, active- controlled phase III trials}

Most importantly, two multicenter, randomized, double-blind, active-controlled phase III studies have been completed on the use of tapentadol prolonged release (PR) in moderateto-severe cancer pain: one Asian study was performed in Japan and Korea, ${ }^{22}$ and the other trial was a multi-national multicenter study from Europe. ${ }^{23,24}$ Table 1 summarizes the key elements of these two pivotal studies.

The Asian study was conducted in 343 patients with a moderate-to-severe pain. They were randomly assigned, in a double-blind fashion, to either tapentadol PR 25-200 mg twice daily or oxycodone controlled release (CR) 5-40 mg twice daily for 4 weeks and were then followed post-treatment for another week. ${ }^{22}$ Oral morphine immediate release (IR) $5 \mathrm{mg}$ was allowed as rescue medication for breakthrough pain, without dose limitation. The main goal of the study was to show non-inferiority in efficacy of tapentadol PR vs oxycodone CR. The study populations consisted of opioidnaive Japanese and Korean patients with any type of cancer, mostly within the gastrointestinal and respiratory tract. Over $90 \%$ of patients had metastatic cancer; a baseline pain intensity of 4 or beyond on an 11-point numerical rating scale was a prerequisite for inclusion. Overall, tapentadol PR was non-inferior to oxycodone CR: both treatments reduced average pain intensities by $2.6-2.7$ points on the 11 -point rating scale, respectively. Most importantly, there was no difference between the tapentadol PR-treated group and the patients treated with oxycodone $\mathrm{CR}$ in the need for rescue medication, or in the mean total daily rescue doses of oral morphine IR tablets, thus confirming that non-inferiority was not due to a difference in rescue medication use. Moreover, 
Table I Key elements from randomized controlled clinical trials on tapentadol PR in the treatment of cancer pain

\begin{tabular}{|c|c|c|c|c|c|c|}
\hline Study & Design & $\begin{array}{l}\text { Patients } \\
\text { randomized }\end{array}$ & $\begin{array}{l}\text { Tapentadol PR } \\
\text { median modal } \\
\text { daily dose }^{\mathrm{a}}\end{array}$ & $\begin{array}{l}\text { Duration study } \\
\text { treatment }\end{array}$ & $\begin{array}{l}\text { Efficacy on } \\
\text { pain (primary } \\
\text { endpoint) }\end{array}$ & Safety \\
\hline $\begin{array}{l}\text { Imanaka } \\
\text { et } \mathrm{al}^{22}\end{array}$ & $\begin{array}{l}\text { Randomized, } \\
\text { double-blind, } \\
\text { active-controlled } \\
\text { (oxycodone CR), } \\
\text { multicenter phase } \\
\text { III study. } \\
\text { Rescue medication: } \\
\text { morphine IR } 5 \text { mg } \\
\text { as needed }\end{array}$ & $\begin{array}{l}\text { Asia: } 343 \text { opioid- } \\
\text { naive patients } \\
\text { with moderate- } \\
\text { to-severe, chronic } \\
\text { malignant tumor- } \\
\text { related pain }\end{array}$ & $\begin{array}{l}\text { TDD: } 50.0 \mathrm{mg} \\
\text { Allowed dose } \\
\text { range: } 25-200 \mathrm{mg} \\
\text { twice daily }\end{array}$ & Median: 28 days & $\begin{array}{l}\text { Mean difference } \\
\text { in the change } \\
\text { in pain intensity } \\
\text { (baseline vs } 3 \text { last } \\
\text { days of treatment, } \\
\text { tapendatol PR vs } \\
\text { oxycodone CR): } \\
-0.06(95 \% \mathrm{Cl} \text { : } \\
-0.506-0.383)^{\mathrm{b}}\end{array}$ & $\begin{array}{l}\text { Patients with at } \\
\text { least one TEAE: } \\
\text { Tapentadol } \\
\text { PR } 87.5 \% \text { vs } \\
\text { oxycodone CR } \\
90.1 \% \\
\text { Patients with } \\
\text { at least one } \\
\text { gastrointestinal } \\
\text { TEAE: } \\
\text { Tapentadol } \\
\text { PR 55.4\% vs } \\
\text { oxycodone CR } \\
67.4 \%\end{array}$ \\
\hline $\begin{array}{l}\text { Kress } \\
\text { et } \mathrm{al}^{23}\end{array}$ & $\begin{array}{l}\text { Randomized } \\
\text { withdrawal, parallel } \\
\text { group, active } \\
\text { (morphine CR) and } \\
\text { placebo-controlled, } \\
\text { double-blind, } \\
\text { multicenter phase } \\
\text { III study. } \\
\text { Rescue medication: } \\
\text { Morphine IR I0 mg } \\
\text { as needed }\end{array}$ & $\begin{array}{l}\text { Europe: } 496 \\
\text { opioid-pretreated } \\
\text { or opioid-naive } \\
\text { patients with } \\
\text { moderate-to- } \\
\text { severe, chronic } \\
\text { malignant tumor- } \\
\text { related pain. } \\
2 / 3 \text { with } \\
\text { neuropathic pain } \\
\text { component }\end{array}$ & $\begin{array}{l}\text { TDD: } 300 \mathrm{mg} \\
\text { Allowed dose } \\
\text { range: } 100-250 \mathrm{mg} \\
\text { twice daily }\end{array}$ & $\begin{array}{l}\text { Median: I4 days of } \\
\text { titration period, } \\
\text { followed by re- } \\
\text { randomization for } \\
\text { another } 28 \text {-day } \\
\text { maintenance period }\end{array}$ & $\begin{array}{l}\text { Responder rate at } \\
\text { the end of titration: } \\
\text { tapentadol PR } \\
76.0 \% \text {, morphine } \\
C R \text { 83.0\% ( } P=0.00 \text { I } \\
\text { for non-inferiority) } \\
\text { Adjusted responder } \\
\text { rate during } \\
\text { maintenance } \\
\text { (primary endpoint): } \\
64.3 \% \text { with } \\
\text { tapentadol, } 47.1 \% \\
\text { with placebo } \\
(P=0.02)\end{array}$ & $\begin{array}{l}\text { During titration: } \\
\text { incidence of } \\
\text { TEAEs: } 50.0 \% \text { with } \\
\text { tapentadol, } 63.9 \% \\
\text { with morphine. } \\
\text { Incidence of nausea, } \\
\text { vomiting, and dry } \\
\text { mouth significantly } \\
\text { lower with } \\
\text { tapentadol PR than } \\
\text { with morphine CR } \\
\text { (P<0.0039) } \\
\text { During } \\
\text { maintenance: } \\
\text { incidences of } \\
\text { TEAEs were } 56.3 \% \\
\text { with placebo, } 62.3 \% \\
\text { (66/I06) with } \\
\text { tapentadol PR, and } \\
62.4 \% \text { (68/I09) with } \\
\text { morphine CR }\end{array}$ \\
\hline
\end{tabular}

Note: a Median modal daily dose $=$ most frequently used daily dose. ${ }^{b}$ Non-inferiority.

Abbreviations: CR, controlled release; IR, immediate release; PR, prolonged release; TDD, total daily dose; TEAE, treatment-emergent adverse events.

tapentadol PR was at least as effective in cancer-related pain relief as oxycodone CR in terms of response ( $\geq 30$ or $\geq 50 \%$ decrease in pain intensity compared with baseline). Lastly, the Patient Global Impression of Change also showed that tapentadol was at least as good as oxycodone in providing sufficient pain relief: $58.7 \%$ of the patients treated with tapentadol PR reported a much improved or improved pain vs $50.4 \%$ in the oxycodone CR-treated group. Remarkably, a significantly lower rate of constipation was reported with tapentadol compared with oxycodone. Overall, the Asian trial in opioid-naive patients with moderate-to-severe chronic malignant tumor-related pain revealed an effective pain relief at tapentadol PR dosages of 25-200 mg twice daily, and non-inferiority to oxycodone $\mathrm{CR}$ at dosages between 5 and $40 \mathrm{mg}$ twice daily.

The European phase III trial evaluated the efficacy and tolerability of tapentadol PR compared with placebo and morphine $\mathrm{CR}$ for managing moderate-to-severe chronic malignant tumor-related pain. ${ }^{23}$ Differing from the Asian study, the European trial investigated the effect of tapentadol PR in cancer patients with chronic, moderate-to-severe, malignant tumor-related pain, who were either opioid-naive or opioid-pretreated with morphine or another opioid drug up to a maximum dose of $160 \mathrm{mg}$ morphine equivalent per 
day, and who were dissatisfied with their prior analgesic medication. This was obviously a different patient population compared with the purely opioid-naive patients recruited in the Asian study. Moreover, the design of the European study was much more complex than the design of the Asian study. Patients with a cancer-related pain of 5 or more on the 11-point numerical rating scale (NRS) were randomly assigned, in a 2:1 ratio, to either tapentadol PR titration up to $100-250 \mathrm{mg}$ twice daily or to a morphine CR titration ranging from 40 up to $100 \mathrm{mg}$ twice daily. This titration period took 2 weeks and involved 496 patients. Thereafter, the individuals were again randomized: those who were on tapentadol during titration were randomized 1:1 to continue with tapentadol at the last dose or to be withdrawn from tapentadol and start receiving placebo. In order not to unblind the morphine sulfate-treated patient group, they were also pseudo-randomized but continued, in a blinded fashion, on their last morphine CR medication reached at the end of the titration period. This second trial period, with three arms including the enriched-withdrawal design for the tapentadol PR group, is referred to as the maintenance period in the following and lasted another 28 days.

The majority of evaluated patients suffered from breast cancer, cancer of the respiratory tract or prostate cancer; $80 \%$ presented metastases, mainly of bones or lymph nodes. One-third of the patients in each arm was $>56$ years of age, gender and body mass index did not show any differences between the groups. In both groups, two-thirds of the patients suffered also from neuropathic pain, whereas neuropathic pain was not recorded in the Asian study.

The primary efficacy endpoint was the rate of responders at the end of the 4-week maintenance period. A responder was defined as a patient who completed the 28 days of maintenance and showed a mean pain intensity score $<5$ on NRS and used only $20 \mathrm{mg}$ or less of rescue morphine medication per day on average. There was a significant difference in favor of a higher responder rate in the tapentadol PR group compared with placebo. Therefore, tapentadol PR proved effective in moderate-to-severe cancer pain, although the comparator placebo group had also access to morphine IR rescue medication.

During the totally blinded 2-week titration period, patients taking tapentadol PR could directly be compared with those taking morphine $\mathrm{CR}$ for titration. At the end of the titration period, responders were again defined as those patients who completed the titration phase, showing a mean pain intensity score $<5$ and having used only $20 \mathrm{mg}$ per day or less of additional morphine IR rescue medication. Again, clear non-inferiority of tapentadol PR vs morphine CR could be shown at a dose ratio of 2.5:1 during the titration phase, and the study endpoint was reached. This dose ratio was also reconfirmed, when the medium modal daily doses of tapentadol PR and morphine CR were compared during the titration ( $300 \mathrm{mg}$ for tapentadol PR vs $120 \mathrm{mg}$ median modal daily dose for morphine $\mathrm{CR}$ ).

When only those patients with a neuropathic pain component were analyzed, there was a tendency of higher response rate to tapentadol, which did not reach statistical significance in this relatively small sample, however.

Similar to the Asian study results, significantly lower percentages of patients with any treatment-emergent adverse events were seen in the tapentadol PR compared with the morphine CR group. In particular, 29.6\% the gastrointestinal disorders were significantly lower under tapentadol PR compared with $46.8 \%$ in the morphine CR group. Similarly, fewer side effects in the nervous system and fewer general disorders were reported under tapentadol, but this did not reach statistical significance.

A separately published post hoc analysis of the European trial investigated the efficacy and tolerability of tapentadol PR in patients who were dissatisfied with their previous tramadol treatment and who had a pain intensity $\geq 5$ on NRS before converting to tapentadol PR $(n=129) .{ }^{24}$ Results for this subgroup were compared with results for all patients who received tapentadol PR during titration $(n=338)$. The responder rates were slightly better for the tramadol/tapentadol PR subgroup vs the overall tapentadol PR group (69.8 vs $63.9 \%$ ). Tolerability profiles were comparable. Overall, these findings suggest that in patients with cancer pain switching from tramadol to tapentadol is feasible, well tolerated and likely associated with improved analgesic efficacy.

\section{Open-label or observational tapentadol studies}

In a separate study from Japan, Imanaka et $\mathrm{a}^{25}$ evaluated the conversion to oral tapentadol PR (50-250 mg twice daily) from previous around-the-clock strong opioid therapy in patients with moderate-to-severe, well-controlled, tumorrelated cancer pain. This randomized, open-label, phase III study consisted of a 1- to 2-week screening period (still on the previous opioid) followed by an 8-week, open-label period. Eligible patients were randomly assigned to receive twice-daily treatment with tapentadol PR (100-500 mg/day) or morphine CR (20-140 mg/day). The primary endpoint was the proportion of patients who maintained pain control (change from baseline in mean pain intensity on NRS $<1.5$ 
for three consecutive days and no more than two doses of rescue medication/day for three consecutive days) during the first week of open-label treatment. In the tapentadol PR group ( $\mathrm{n}=50), 84.0 \%$ of patients kept pain control during week 1, compared with $98 \%$ with morphine. Tapentadol PR was associated with a lower incidence of gastrointestinal treatment-emergent adverse events than morphine $(38.0 \%$ vs $54.0 \%)$, including constipation $(12.0 \%$ vs $20.0 \%)$ and vomiting (6.0\% vs $26.0 \%)$.

Mercadante et $\mathrm{al}^{26}$ conducted a 4 -week prospective study in 50 opioid-naive cancer patients with moderate-to-severe pain; each patient received twice-daily doses of tapentadol PR $50 \mathrm{mg}$, and doses were then titrated according to clinical response. In total, 39 patients completed the study. Pain intensity significantly decreased from baseline starting from week 1 , and quality of life improved over the study period. Tapentadol escalation indexes were low and no correlation with age, gender and pain mechanisms was reported. Importantly, no worsening of clinical status was documented, and tapentadol was also well tolerated in patients previously on NSAIDs/paracetamol.

An open-label, prospective, noninterventional study in 123 cancer pain patients, $42.3 \%$ of whom were on strong opioids prior to the initiation of tapentadol treatment, documented a significantly lower mean pain intensity on NRS by the end of the 3-month observation period after the switch to tapentadol PR treatment. This finding was consistent for "lowest pain intensity" as well as for "average pain intensity" and "highest pain intensity." Patients were very satisfied with the tapentadol treatment of their cancer-related pain under these real-life conditions: the majority of patients very much improved or at least improved in their general condition after the switch to tapentadol. ${ }^{27}$

Finally, Cascella et $\mathrm{al}^{28}$ have recently published the results of an observational prospective study in 80 cancer patients, either opioid-naive or pretreated. In total, 70 out of 80 patients $(88 \%)$ were responders. Compared to baseline, a decrease in pain intensity was reported at all assessments, till day 70 of treatment. Only two patients $(2.5 \%)$ left the study for tapentadol-related adverse events. A significant improvement in quality of life was noticeable after 30-40 days, and the majority of patients were "satisfied," "very satisfied," or "extremely satisfied" with treatment.

In clinical practice, it has been observed that switching a patient from a high dose of a strong $\mu$-opioid to an equianalgesic dose of tapentadol PR may lead to features of mild acute opioid withdrawal, thus confirming that tapentadol cannot simply be considered another opioid. ${ }^{19}$ This issue has been investigated in two studies by Mercadante et al;29,30 the overall results show that, for average doses, the switch is feasible and well tolerated, also in opioid-pretreated patients.

\section{Tapentadol in patients with pain related to hematological malignancies}

Myeloma bone disease is a major complication of multiple myeloma associated with severe pain. Coluzzi et a ${ }^{31}$ prospectively evaluated the efficacy and tolerability of tapentadol PR in the management of 25 patients with myeloma bone disease, who were opioid-naive with moderate-to-severe pain. Patients initially received tapentadol PR $50 \mathrm{mg}$ twice daily, and doses were titrated according to clinical needs. In total, 22 patients completed the study. Pain intensity significantly decreased from baseline as early as at week $1(P<0.01)$; this improvement in pain intensity was paralleled by improved quality of life, as assessed by the SF-36 scale. Tapentadol PR was also associated with a reduction in DN4 (Douleur Neuropathique 4$)$ mean values $(P<0.01)$, which can be useful for distinguishing neuropathic from nociceptive pain. ${ }^{32}$ During tapentadol therapy, the number of patients showing a neuropathic component of pain (DN4 $\geq 4$ ) significantly decreased $(P<0.01)$. At week 8 , all patients were negative for neuropathic pain by means of the DN4 score. Tapentadol PR was well tolerated, and the use of other analgesics reduced over the study period. Overall, the authors of the study concluded that tapentadol PR can be considered a first-choice opioid in cancer patients suffering from mixed pain with a neuropathic component.

In a retrospective study specifically conducted in 36 challenging ( $N R S \geq 5$ ) patients with hematological malignancies and uncontrolled pain, Brunetti et a ${ }^{33}$ explored the safety and efficacy of tapentadol PR. Overall, a remarkable ( -7 points out of 11) reduction of pain intensity was reported, without any relevant adverse event.

\section{Tapentadol in cancer treatment- related pain}

Mucositis is a frequent and painful side effect of chemotherapy and radiotherapy. Mazzola et $\mathrm{a} \mathrm{l}^{34}$ evaluated the effectiveness and tolerability profile of tapentadol PR in a cohort study of 30 opioid-naive head and neck cancer patients with background pain due to painful mucositis during intensitymodulated radiation therapy with or without cisplatin with either definitive or adjuvant intent. Tapentadol PR $50 \mathrm{mg}$ twice daily was given at pain onset; this dosage could be increased according to clinical needs. The observation period 
was 90 days from the start of antineoplastic treatment: 22 days after the initiation of antineoplastic treatment, tapentadol PR was administered to $25 \%$ of patients. This percentage increased to $50 \%$ after 39 days and to $75 \%$ after 43 days. A reduction by $30 \%$ of pain intensity in 26 patients $(86.7 \%)$, and a reduction of $50 \%$ in 23 patients $(76.7 \%)$ were reported.

Many chemotherapeutic agents can induce peripheral neuropathy (CIPN), and patients with CIPN often experience neuropathic pain. Galiè et $\mathrm{al}^{35}$ conducted a prospective, open-label study to evaluate the efficacy and tolerability of tapentadol PR in patients with CIPN secondary to taxaneand/or platinum-based regimens. After 3-month treatment with tapentadol, 22 patients were evaluated, with $19(86 \%)$ of them showing a response (NRS reduction $\geq 3$ vs baseline). Tapentadol also reduced NRS and DN4 values from baseline to the last visit, and an improvement of their health status as measured by the European Organization for Research and Treatment of Cancer Quality-of-Life Questionnaire Core 30 (EORTC-QLQ-C30) was reported.

\section{Conclusions}

In all clinical studies with cancer pain patients, tapentadol PR was well tolerated and provided adequate analgesia, which was at least non-inferior to the standard opioids morphine CR or oxycodone CR. Based on the high level of evidence derived from two independent randomized, double-blind, active-controlled phase III trials (one of which was larger than any trial on opioids in this setting), together with the admittedly weaker evidence from various open-label or observational clinical studies, tapentadol PR can be considered a universal, strong, centrally acting analgesic drug for the management of moderate-to-severe cancer pain, both in opioid-naive and already opioid-pretreated patients. Its good analgesic efficacy seems to be due, at least in part, to the inherent synergistic mechanisms of tapentadol acting also on neuropathic components of cancer pain.

Remarkably, a Cochrane review, published in 2015, revealed that tapentadol appeared at least as effective as morphine or oxycodone in pain relief for cancer patients. ${ }^{36}$ This finding might have immediate clinical relevance given the mounting importance of opioid rotation for pain therapy in oncological patients: tapentadol can represent an alternative within this approach. ${ }^{37}$ Moreover, it is worth noticing that many cancer patients do show hepatic decompensation, thus limiting the use of tramadol. ${ }^{38}$

Preliminary evidence indicates that tapentadol PR might be also a suitable therapy for pain associated with oncological treatments, such as intensity-modulated radiotherapy or chemotherapy.
The reduced occurrence of gastrointestinal adverse effects and the overall favorable safety profile of tapentadol may be an advantage in cancer pain patients, who frequently - and because of multiple causes - suffer from nausea or vomiting, constipation or other events that further reduce their already poor quality of life. The low potential of tapentadol for undergoing drug-drug interactions is another important advantage in the setting of cancer patients under extensive pharmacological therapy. For all these reasons, tapentadol can be considered a suitable option for supportive care in those vulnerable cancer patients, who are particularly prone to experience gastrointestinal adverse events.

\section{Key points}

- Pain in cancer patients is often undertreated and can have both nociceptive and neuropathic components.

- Traditional opioids may not be best choice in all cancer patients with pain, since they do not always act on the neuropathic components of their pain, and are associated with a higher risk of adverse events and drug-drug interactions compared with tapentadol.

- In cancer pain patients, tapentadol PR was well tolerated and effective, and therefore can be considered a universal analgesic to be used for the management of moderate-tosevere cancer pain in opioid-naive and opioid-pretreated patients.

- The good analgesic efficacy may be due, at least in part, to the action of tapentadol on neuropathic components of pain.

- The lower rate of gastrointestinal adverse effects and the overall favorable safety profile of tapentadol compared to other opioid analgesics may be of advantage in cancer patients frequently suffering from nausea, vomiting, constipation or other events that further reduce their quality of life.

- The low potential for drug-drug interactions is another favorable property of tapentadol in cancer patients under extensive pharmacological therapy.

\section{Acknowledgments}

Editorial assistance was provided by Luca Giacomelli, $\mathrm{PhD}$ and Aashni Shah. This assistance and fees for publications were supported by Grunenthal.

\section{Disclosure}

HGK has received speaker's and/or consultancy fees from Bionorica SE, Grunenthal GmbH, Mundipharma Int., TEVA Ratiopharm, Mylan, and Pfizer outside the submit- 
ted work. The authors report no other conflicts of interest in this work.

\section{References}

1. Oldenmenger WH, Geerling JI, Mostovaya I, et al. A systematic review of the effectiveness of patient-based educational interventions to improve cancer-related pain. Cancer Treat Rev. 2018;63:96-103.

2. van den Beuken-van Everdingen MH, Hochstenbach LM, Joosten EA, Tjan-Heijnen VC, Janssen DJ. Update on prevalence of pain in patients with cancer: systematic review and meta-analysis. J Pain Symptom Manage. 2016;51(6):1070-1090.

3. von Moos R, Costa L, Ripamonti CI, Niepel D, Santini D. Improving quality of life in patients with advanced cancer: targeting metastatic bone pain. Eur J Cancer. 2017;71:80-94.

4. Caraceni A, Hanks G, Kaasa S, et al. European palliative care research collaborative (EPCRC); European association for palliative care (EAPC). Use of opioid analgesics in the treatment of cancer pain: evidence-based recommendations from the EAPC. Lancet Oncol. 2012;13:e58-68.

5. Jara C, del Barco S, Grávalos C, et al. SEOM clinical guideline for treatment of cancer pain (2017). Clin Transl Oncol. 2018;20(1):97-107.

6. Mirabile A, Airoldi M, Ripamonti C, et al. Pain management in head and neck cancer patients undergoing chemo-radiotherapy: clinical practical recommendations. Crit Rev Oncol Hematol. 2016;99:100-106.

7. Ripamonti CI, Santini D, Maranzano E, Berti M, Roila F. ESMO guidelines Working Group. Management of cancer pain: ESMO clinical practice guidelines. Ann Oncol. 2012;23(Suppl 7):vii139-154.

8. O'Brien T, Christrup LL, Drewes AM, et al. European Pain Federation position paper on appropriate opioid use in chronic pain management. Eur J Pain. 2017;21(1):3-19.

9. Breivik H, Cherny N, Collett B, et al. Cancer-related pain: a panEuropean survey of prevalence, treatment, and patient attitudes. Ann Oncol. 2009;20(8):1420-1433.

10. Vellucci R, Mediati RD, Gasperoni S, Mammucari M, Marinangeli F, Romualdi P. Assessment and treatment of breakthrough cancer pain: from theory to clinical practice. J Pain Res. 2017;10:2147-2155.

11. Reis-Pina P, Lawlor PG, Barbosa A. Adequacy of cancer-related pain management and predictors of undertreatment at referral to a pain clinic. J Pain Res. 2017;10:2097-2107.

12. Ripamonti CI, Santini D, Maranzano E, Berti M, Roila F. ESMO guidelines Working Group. Management of cancer pain: ESMO clinical practice guidelines. Ann Oncol. 2012;23(Suppl 7):vii139-vii154.

13. Fallon MT. Neuropathic pain in cancer. Br J Anaesth. 2013;111(1): 105-111.

14. Bennett MI, Rayment C, Hjermstad M, Aass N, Caraceni A, Kaasa S. Prevalence and aetiology of neuropathic pain in cancer patients: a systematic review. Pain. 2012;153(2):359-365.

15. Mantyh PW. Bone cancer pain: from mechanism to therapy. Curr Opin Support Palliat Care. 2014;8(2):83-90.

16. Currie GL, Delaney A, Bennett MI, et al. Animal models of bone cancer pain: systematic review and meta-analyses. Pain. 2013;154(6):917-926.

17. Portenoy RK, Ahmed E. Principles of opioid use in cancer pain. J Clin Oncol. 2014;32(16):1662-1670.

18. Kress HG. Tapentadol and its two mechanisms of action: is there a new pharmacological class of centrally-acting analgesics on the horizon? Eur J Pain. 2010;14(8):781-783.

19. Langford RM, Knaggs R, Farquhar-Smith P, Dickenson AH. Is tapentadol different from classical opioids? A review of the evidence. $\mathrm{Br} J$ Pain. 2016;10(4):217-221.
20. Raffa RB, Elling C, Tzschentke TM. Does 'strong analgesic' equal 'strong opioid'? Tapentadol and the concept of ' $\mu$-load'. Adv Ther. 2018;35(10):1471-1484.

21. Pergolizzi JV, Lequang JA, Taylor R, Ossipov MH, Colucci D, Raffa RB. Designing safer analgesics: a focus on $\mu$-opioid receptor pathways. Expert Opin Drug Discov. 2018;13(10):965-972.

22. Imanaka K, Tominaga Y, Etropolski M, et al. Efficacy and safety of oral tapentadol extended release in Japanese and Korean patients with moderate to severe, chronic malignant tumor-related pain. Curr Med Res Opin. 2013;29(10):1399-1409.

23. Kress HG, Koch ED, Kosturski H, et al. Tapentadol prolonged release for managing moderate to severe, chronic malignant tumor-related pain. Pain Physician. 2014;17(4):329-343.

24. Kress HG, Koch ED, Kosturski H, et al. Direct conversion from tramadol to tapentadol prolonged release for moderate to severe, chronic malignant tumour-related pain. Eur J Pain. 2016;20(9):1513-1518.

25. Imanaka K, Tominaga Y, Etropolski M, Ohashi H, Hirose K, Matsumura T. Ready conversion of patients with well-controlled, moderate to severe, chronic malignant tumor-related pain on other opioids to tapentadol extended release. Clin Drug Investig. 2014;34(7):501-511.

26. Mercadante $S$, Porzio G, Ferrera $P$, et al. Tapentadol in cancer pain management: a prospective open-label study. Curr Med Res Opin. 2012;28(11): 1775-1779.

27. Schikowski A, Krings D, Schwenke K. Tapentadol prolonged release for severe chronic cancer-related pain: effectiveness, tolerability, and influence on quality of life of the patients. J Pain Res. 2015;8:1-8.

28. Cascella M, Forte CA, Bimonte S, et al. Multiple effectiveness aspects of tapentadol for moderate-severe cancer-pain treatment: an observational prospective study. J Pain Res. 2019;12:117-125.

29. Mercadante S, Porzio G, Aielli F, et al. Opioid switching from and to tapentadol extended release in cancer patients: conversion ratio with other opioids. Curr Med Res Opin. 2013;29(6):661-666.

30. Mercadante S, Porzio G, Adile C, et al. Tapentadol at medium to high doses in patients previously receiving strong opioids for the management of cancer pain. Curr Med Res Opin. 2014;30(10):2063-2068.

31. Coluzzi F, Raffa RB, Pergolizzi J, et al. Tapentadol prolonged release for patients with multiple myeloma suffering from moderate-to-severe cancer pain due to bone disease. J Pain Res. 2015;8:229-238.

32. Bouhassira D, Attal N, Alchaar H, et al. Comparison of pain syndromes associated with nervous or somatic lesions and development of a new neuropathic pain diagnostic questionnaire (DN4). Pain. 2005;114(1-2): 29-36.

33. Brunetti GA, Palumbo G, Morano GS, et al. Tapentadol PR for pain syndromes in real life patients with hematological malignancy. Cardiovasc Hematol Agents Med Chem. 2016;14(1):68-74.

34. Mazzola R, Ricchetti F, Fersino S, et al. Erratum: Erratum to: effectiveness of tapentadol prolonged release for the management of painful mucositis in head and neck cancers during intensity modulated radiation therapy. Support Care Cancer. 2016;24(10):4457-5.

35. Galiè E, Villani V, Terrenato I, Pace A. Tapentadol in neuropathic pain cancer patients: a prospective open label study. Neurol Sci. 2017;38(10): 1747-1752.

36. Wiffen PJ, Derry S, Naessens K, Bell RF. Oral tapentadol for cancer pain. Cochrane Database Syst Rev. 2015;9:CD011460.

37. Treillet E, Laurent S, Hadjiat Y. Practical management of opioid rotation and equianalgesia. J Pain Res. 2018;11:2587-2601.

38. Bosilkovska M, Walder B, Besson M, Daali Y, Desmeules J. Analgesics in patients with hepatic impairment: pharmacology and clinical implications. Drugs. 2012;72(12):1645-1669. 


\section{Publish your work in this journal}

The Journal of Pain Research is an international, peer reviewed, open access, online journal that welcomes laboratory and clinical findings in the fields of pain research and the prevention and management of pain. Original research, reviews, symposium reports, hypothesis formation and commentaries are all considered for publication.

Submit your manuscript here: https://www.dovepress.com/journal-of-pain-research-journal

The manuscript management system is completely online and includes a very quick and fair peer-review system, which is all easy to use. Visit http://www.dovepress.com/testimonials.php to read real quotes from published authors. 